Advances in Radio Science (2004) 2: 253-258

(c) Copernicus GmbH 2004

\title{
Investigations of long-term trends in the ionosphere with world-wide ionosonde observations*
}

\author{
J. Bremer \\ Leibniz-Institut für Atmosphärenphysik, Schloss-Str.6, D-18225 Kühlungsborn, Germany \\ * Dedicated to Prof. Dr. K. Rawer on the occasion of his 90th birthday.
}

\begin{abstract}
Basing on model calculations by Roble and Dickinson (1989) for an increasing content of atmospheric greenhouse gases in the Earth's atmosphere Rishbeth (1990) predicted a lowering of the ionospheric F2- and E-regions. Later Rishbeth and Roble (1992) also predicted characteristic longterm changes of the maximum electron density values of the ionospheric E-, F1-, and F2-layers. Long-term observations at more than 100 ionosonde stations have been analyzed to test these model predictions. In the E- and F1-layers the derived experimental results agree reasonably with the model trends (lowering of $h^{\prime} \mathrm{E}$ and increase of $f o \mathrm{E}$ and $f o \mathrm{~F} 1$, in the E-layer the experimental values are however markedly stronger than the model data). In the ionospheric F2-region the variability of the trends derived at the different individual stations for $h m \mathrm{~F} 2$ as well as $f o \mathrm{~F} 2$ values is too large to estimate reasonable global mean trends. The reason of the large differences between the individual trends is not quite clear. Strong dynamical effects may play an important role in the F2-region. But also inhomogeneous data series due to technical changes as well as changes in the evaluation algorithms used during the long observation periods may influence the trend analyses.
\end{abstract}

\section{Introduction}

The estimation of ionospheric long-term trends is an important scientific topic for the investigation of possible anthropogenic changes in the Earth's atmosphere. Whereas an increasing content of atmospheric greenhouse gases $\left(\mathrm{CO}_{2}\right.$, $\mathrm{CH}_{4}, \mathrm{H}_{2} \mathrm{O}, \ldots$ ) should cause increasing temperatures near the Earth's surface and in the troposphere (Hegerl et al., 1996) in the strato-, meso-, and thermosphere the temperatures should be reduced by an increasing cooling due to an enhanced infrared radiation of the greenhouse gases into space (Roble and Dickinson, 1989). Therefore, Rishbeth (1990) and Rish-

Correspondence to: J. Bremer

(bremer@iap-kborn.de) beth and Roble (1992) predicted a shrinking of the ionosphere as well as characteristic changes of the maximum electron densities in the ionospheric E-, F1-, and F2-layers.

Data of ionosonde observations which are regularly derived at many different stations around the Earth since more than 40 or even 50 years can be used for trend analyses using different standard parameters. In this paper the following parameters have been analyzed: the maximum electron densities of different ionospheric layers characterized by their critical frequencies $f o \mathrm{E}, f o \mathrm{~F} 1$, and $f o \mathrm{~F} 2$ as well as the height parameters $h^{\prime} \mathrm{E}$ and $h m \mathrm{~F} 2$. The height of the maximum of the F2-layer, $h m \mathrm{~F} 2$, has been derived from $\mathrm{M}(3000) \mathrm{F} 2$ ionosonde values using the well-known simple formula derived by Shimazaki (1955).

Most of the data for more than 100 different ionosonde stations have been selected from CD-ROMs of NGDC, Boulder, USA, and from WDC-C at RAL, Chilton, UK.

\subsection{Data analysis method}

In Fig. 1 some examples of long-term variations are shown using $f o \mathrm{~F} 2$ and $h m \mathrm{~F} 2$ data (noon values for June and December) observed at the station Juliusruh $\left(54.6^{\circ} \mathrm{N}, 13.4^{\circ} \mathrm{E}\right)$ during the time period between 1957 and 2002. Both parameters are characterized by a marked 11-yearly variation caused by changes of the solar and geomagnetic activity shown in the lower part of Fig. 1. Here the solar sunspot number $R$ is used as an index of the solar wave radiation and the geomagnetic $A_{p}$ index as a proxy of the fluxes of precipitating high energy particles. These solar and geomagnetically induced variations of the plasma parameters are markedly stronger than possible long-term variations. Therefore, we used the following algorithm to eliminate these influences.

For monthly mean values at each full hour for $X=f o \mathrm{E}, h^{\prime} \mathrm{E}$, $f o \mathrm{~F} 1, f o \mathrm{~F} 2$, or $h m \mathrm{~F} 2$ a twofold regression equation has been derived:

$X_{\text {th }}=a+b \cdot R+c \cdot A_{p}$. 


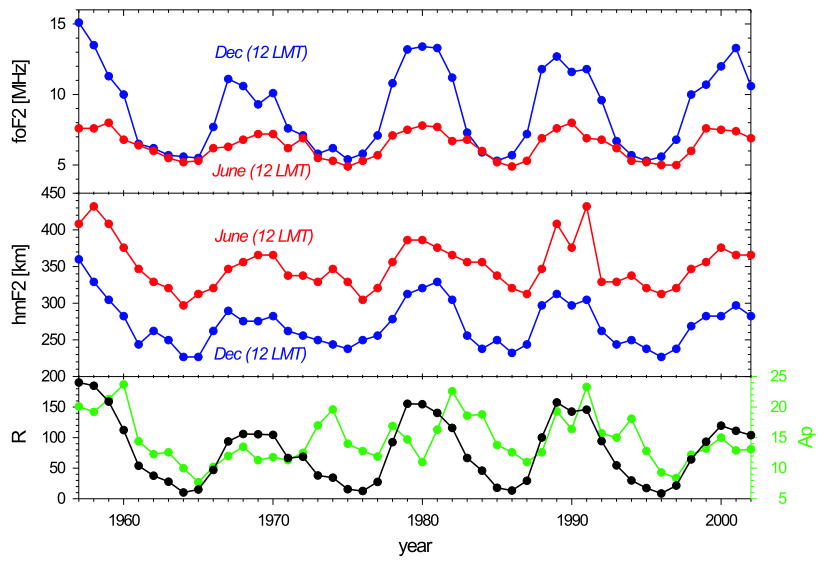

Fig. 1. Long-term variation of $f o \mathrm{~F} 2$ and $h m \mathrm{~F} 2$ for June and December at noon condition from ionosonde observations at Juliusruh $\left(54.6^{\circ} \mathrm{N}, 13.4^{\circ} \mathrm{E}\right)$ together with variations of yearly mean values of solar sunspot number $R$ and geomagnetic $A_{p}$ index.

For the solar activity index also other parameters than $R$ can be used (e.g. solar radio flux F10.7), but the final trend results are not markedly influenced by this choice (Bremer, 2001). The solar and geomagnetically caused part has been subtracted from the corresponding observed values for each month and each hour.

$\Delta X=X_{\mathrm{obs}}-X_{\mathrm{th}}$.

From these hourly data yearly mean $\Delta X$ values have been estimated for the derivation of linear trends

$\Delta X=d+e \cdot$ year

with the trend parameter $b$ measured in MHz/year or $\mathrm{km} / \mathrm{year}$.

\subsection{Experimental trends}

Using the method shortly described in Sect. 1.1 the trends of different parameters observed at the ionosonde station Juliusruh $\left(54.6^{\circ} \mathrm{N}, 13.4^{\circ} \mathrm{E}\right)$ are shown in Fig. 2. Both height parameters, $h m \mathrm{~F} 2$ and $h^{\prime} \mathrm{E}$, have significant negative trends (red curves) in qualitative agreement with the model predictions of Rishbeth (1990), whereas the critical frequencies, $f o \mathrm{E}$, $f o \mathrm{~F} 1, f o \mathrm{~F} 2$, only slightly increase. Their trends are not significant (black curves). Compared with the strong variability of the original data shown in Fig. 1 the amplitudes of the longterm trends presented in Fig. 2 are markedly smaller, thus demonstrating that a careful elimination of the solar and geomagnetically induced variation is necessary to get reasonable trend results.

To get more information about mean global trends in the ionosphere analyses have been extended to data of different ionosonde stations all around the world. In Fig. 3 the results of $f o \mathrm{~F} 1$ trends are presented which have been derived from 51 different stations. In the upper part of this figure a histogram of the individual trends is shown for significant and non significant trends. The median trend is marked by an

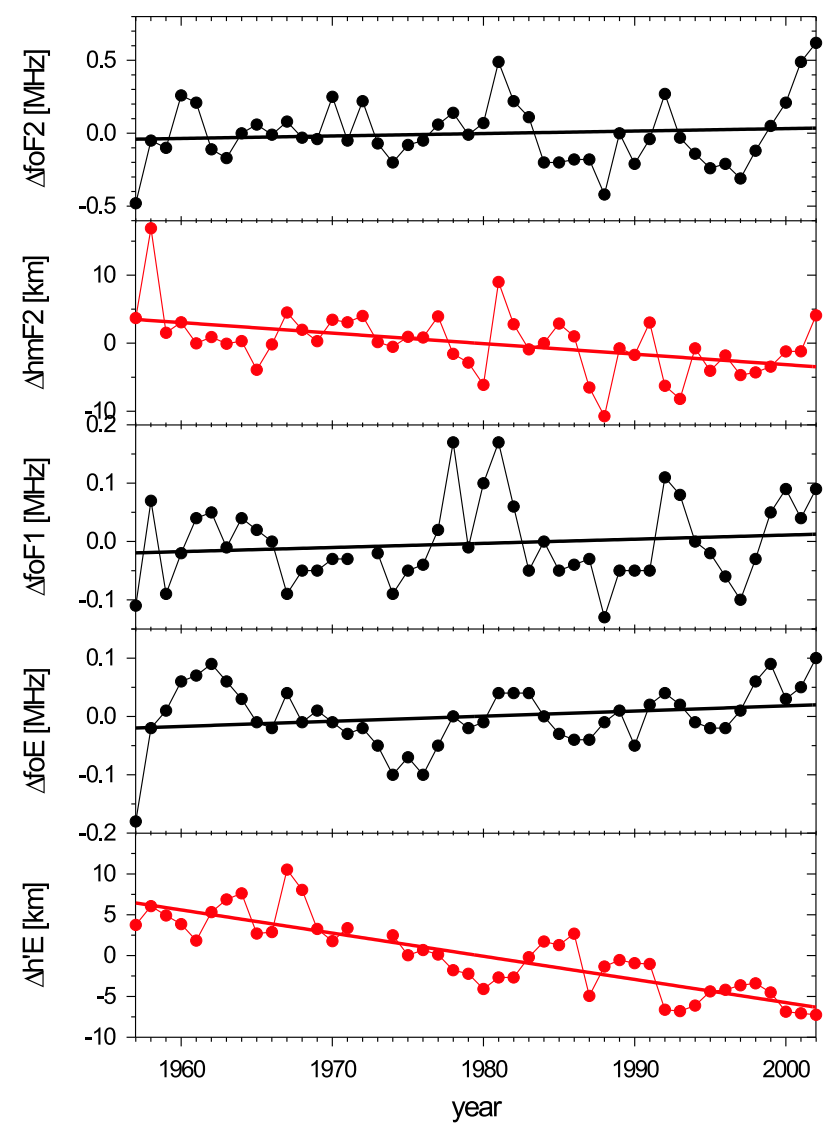

Fig. 2. Long-term trends of different ionospheric parameters observed at Juliusruh after elimination of the solar and geomagnetically induced variations.

arrow. In the lower part all $\Delta X$ values have been averaged and a mean trend was estimated. Both mean trend values derived by the two different methods are nearly identical. Also the estimated mean errors with 95\% reliability level (for details of their estimation see Taubenheim, 1969) are smaller than the estimated mean values demonstrating that the derived global mean trend values are significant different from zero.

In Fig. 4 the histograms for all five investigated ionosonde parameters are shown together with the corresponding median values marked by arrows. The histograms are characterised by relatively broad distributions, mainly for the parameters of the F2-region. Figure 4 is an updated version of a similar picture shown earlier in Bremer (2001). Negative trends are presented by blue, positive trends by red colour. The number in brackets describe the number of individual stations used in the trend analyses. The median trend values of the histograms are collected in Table 1 together with their mean error values (Taubenheim, 1969). It can be seen that only the global mean trends in $f o \mathrm{E}$ and $f o \mathrm{~F} 1$ are significant different from zero with a significance level of more than $95 \%$. For all other cases $\left(h^{\prime} \mathrm{E}, h m \mathrm{~F} 2, f o \mathrm{~F} 2\right)$ the significance level is markedly lower (for $f o \mathrm{~F} 2: 84 \%, h^{\prime} \mathrm{E}: 75 \%, h m \mathrm{~F} 2$ : $<50 \%)$. 
Table 1. Mean experimental trends and error limits (95\%) derived from trend analyses for different ionosonde parameters. $N$ is the number of ionosonde stations used in the estimations of mean trends.

\begin{tabular}{ccccc}
\hline & Parameter & $N$ & Mean trend & Error $(95 \%)$ \\
\hline F2-region & $f o \mathrm{~F} 2$ & 106 & $-0.0018 \mathrm{MHz} /$ year & $\pm 0.0025 \mathrm{MHz} /$ year \\
& $h m \mathrm{~F} 2$ & 87 & $-0.009 \mathrm{~km} /$ year & $\pm 0.076 \mathrm{~km} /$ year \\
F1-region & $f o \mathrm{~F} 1$ & 51 & $0.0027 \mathrm{MHz} /$ year & $\pm 0.0011 \mathrm{MHz} /$ year \\
E-region & $f_{o \mathrm{E}}$ & 72 & $0.0014 \mathrm{MHz} /$ year & $\pm 0.0007 \mathrm{MHz} /$ year \\
& $h^{\prime} \mathrm{E}$ & 31 & $-0.040 \mathrm{~km} /$ year & $\pm 0.070 \mathrm{~km} /$ year \\
\hline
\end{tabular}

Table 2. Mean experimental (exp) trends of different ionospheric parameters and expected changes of these data assuming a doubling of the atmospheric Greenhouse gases $\left(\mathrm{CO}_{2} * 2\right)$. The model data (mod) are from Rishbeth (1990) and Rishbeth and Roble (1992).

\begin{tabular}{ccccc}
\hline & Parameter & Mean exp. Trend & $\mathrm{CO}_{2} * 2(\exp )$ & $\mathrm{CO}_{2} * 2(\mathrm{mod})$ \\
\hline \multirow{2}{*}{ F2-region } & $f o \mathrm{~F} 2$ & $-0.0018 \mathrm{MHz} /$ year & $-0.36 \mathrm{MHz}$ & $-0.2 \ldots-0.5 \mathrm{MHz}$ \\
& $h m \mathrm{~F} 2$ & $-0.009 \mathrm{~km} /$ year & $-1.8 \mathrm{~km}$ & $-10 \ldots-20 \mathrm{~km}$ \\
F1-region & $f o \mathrm{~F} 1$ & $0.0027 \mathrm{MHz} /$ year & $0.54 \mathrm{MHz}$ & $0.3 \ldots 0.5 \mathrm{MHz}$ \\
E-region & $f o \mathrm{E}$ & $0.0014 \mathrm{MHz} /$ year & $0.28 \mathrm{MHz}$ & $0.05 \ldots 0.08 \mathrm{MHz}$ \\
& $h^{\prime} \mathrm{E}$ & $-0.040 \mathrm{~km} /$ year & $-8.0 \mathrm{~km}$ & $-2.5 \mathrm{~km}$ \\
\hline
\end{tabular}

From Fig. 4 and the mean results summarised in Table 1 it became clear that the variability of the individual trends in the F2-region is very strong. Especially the $h m \mathrm{~F} 2$ trends differ markedly between the different stations analysed. In Fig. 5 these individual $h m \mathrm{~F} 2$ trends are shown in dependence on latitude and longitude. Negative trends are marked by blue, positive by red symbols. Full dots represent significant trends $(>95 \%)$, circles non significant trends. Strong regional differences can be observed e.g. with negative trends in Central and Western Europe and positive trends in Central Asia. Also in the $f o \mathrm{~F} 2$ trends some regional differences occur, but not so pronounced as in the $h m \mathrm{~F} 2$ trends.

\section{Discussion}

Can the mean ionosonde trends shown in Table 1 be explained by an increasing atmospheric greenhouse effect? To answer this question the experimental trends have to be compared with model calculations of Rishbeth (1990) and of Rishbeth and Roble (1992). Their theoretical results have been derived for a doubling of the atmospheric greenhouse gases $\mathrm{CO}_{2}$ and $\mathrm{CH}_{4}$. The effective change of the greenhouse gases during the last 40 years where trends of the ionosonde data have been investigated is about 20\% (Brasseur and de Rudder, 1987; Houghton et al., 2001). Assuming a linear dependence between the content of the atmospheric greenhouse gases and the ionospheric effect, the experimental trends can be extrapolated to a level of doubled greenhouse gases. These values called $\mathrm{CO}_{2} * 2(\exp )$ are compared with the corresponding model values $\mathrm{CO}_{2} * 2$ (mod) of Rishbeth (1990) and Rishbeth and Roble (1992) in Table 2.

As to be seen from the data shown in Table 2 in the E-region the experimental and theoretical trend val- ues agree qualitatively with a lowering of the height $h^{\prime} \mathrm{E}$ and an increase of $f o \mathrm{E}$. However the experimental trends are markedly stronger than the model values. The derived positive $f o \mathrm{E}$ trend is also in general agreement with rocket mass spectrometer measurements of the ion density ratio $\left[\mathrm{NO}^{+}\right] /\left[\mathrm{O}_{2}^{+}\right]$in the E-region (Danilov and Smirnova, 1997). The observed negative trends of $\left[\mathrm{NO}^{+}\right] /\left[\mathrm{O}_{2}^{+}\right]$cause increasing electron densities and therefore increasing $f o \mathrm{E}$ values as the dissociative recombination coefficient of $\mathrm{NO}^{+}$is markedly larger than that of $\mathrm{O}_{2}^{+}$.

The agreement of the mean experimental and model trends in the F1-region is surprisingly good as to be seen in Table 2 .

Also in the F2-region the agreement between the experimental and model trends seems to be quite reasonable looking at the data in Table 2. However, the variability of the individual trends at different stations is very strong, and the derived mean trends are not statistically significant different from zero as can be seen in Table 1. Especially the variability of the $h m \mathrm{~F} 2$ trends is very pronounced. Therefore, the agreement between model and experimental data is more accidental. The reason of the strong variability in the F2-region is not quite clear. After Fig. 5 there seem to be regional differences which could be caused by dynamical effects in the plasma of the F2-region. Such strong regional differences of the $h m \mathrm{~F} 2$ trends have also earlier been detected by other authors using a more limited data volume (Ulich and Turunen, 1997; Bremer, 1998; Bencze at al., 1998). From satellite observations (Keating et al., 2000) it is known that the observed long-term neutral density reduction near $350 \mathrm{~km}$ altitude is in good agreement with model calculations of an increasing greenhouse effect (Akmaev, 2002). That means that the possible greenhouse effect in ionospheric data series is superposed by unknown dynamical processes which are 

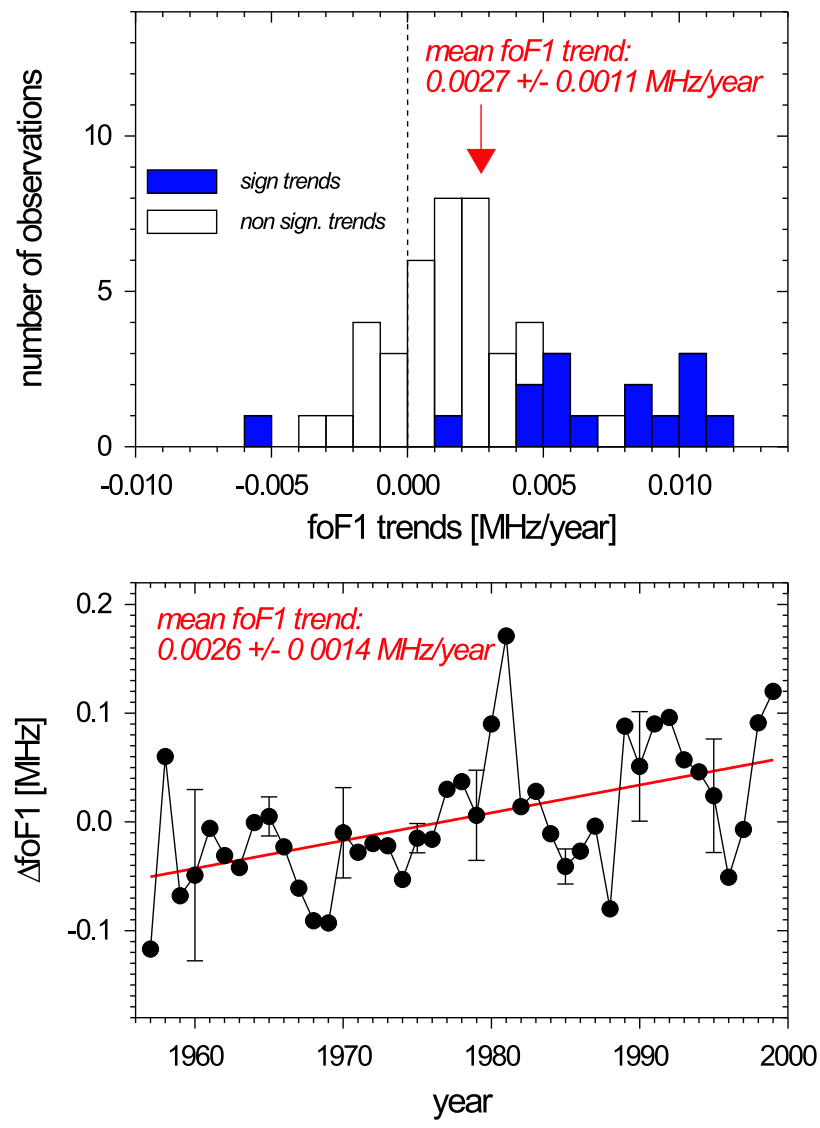

Fig. 3. Mean global $f o \mathrm{~F} 1$ trend deduced from world wide ionosonde observations. Upper part: Histogram of individual trends with median trend marked by an arrow. Lower part: Mean trend deduced from individual trends after elimination of solar and geomagnetic influences.

more important for the variability of the ionized component than for the neutral gas at F2-region heights.

Another reason of differences between trends of (partly neighbouring) stations may be caused by technical changes during the long ionosonde observation periods or by changes of the evaluation algorithms (one possible effect could be caused by changes from manual scaling to automatic scaling of the ionosonde observations). In Fig. 6 some examples of $h m \mathrm{~F} 2$ data series are shown with discontinuities. Similar examples can be found in Bremer (2001) for $h^{\prime}$ E observations.

Taking into account the above mentioned increase of $20 \%$ of the greenhouse gases during the last 40 years, the doubling of the greenhouse gases would be expected for a time period of about 200 years. That means the different ionospheric parameters will change by the $\mathrm{CO}_{2}(\exp )$ values of Table 2 during the next 200 years. Therefore, the expected mean changes of the different ionospheric parameters are not essential for practical purposes and have not to be considered in practical prediction models e.g. for ionospheric HF propagation.
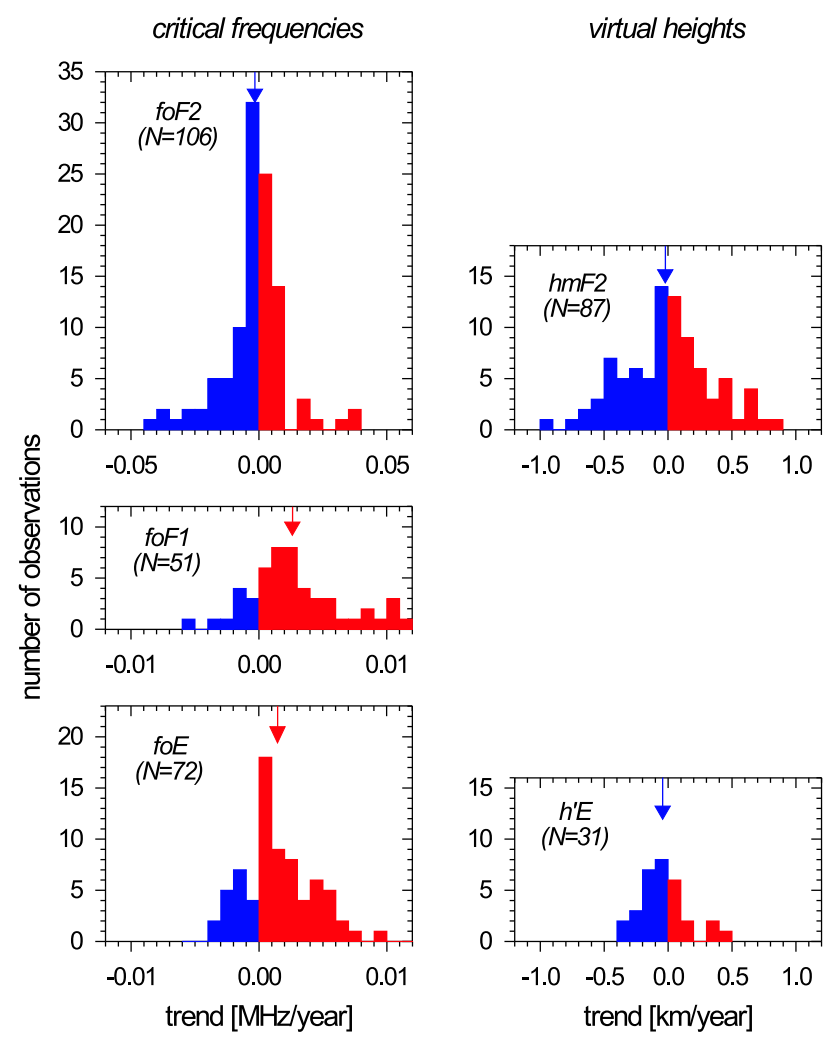

Fig. 4. Histograms of different ionospheric parameters $\left(f_{o} \mathrm{~F} 2, h m \mathrm{~F} 2\right.$, $\left.f o \mathrm{~F} 1, f o \mathrm{E}, h^{\prime} \mathrm{E}\right)$ from world wide ionosonde observations. The median values are marked by arrows. The number of ionosonde stations used in the trend analyses are given in brackets.

\section{Conclusions}

Using data of world wide long-term ionosonde observations trends have been estimated for different characteristic ionospheric parameters in the E-, F1-, and F2-regions. The following conclusions can be given for the most important methodical, practical and scientific aspects:

- Long-term ionosonde data series have carefully to be checked concerning their homogeneity. Discontinuities caused by different technical changes can markedly influence the results of trend analyses.

- The solar and geomagnetically induced variations of the ionospheric parameters are essentially stronger than the long-term trends.

- The long-term trends are unimportant for practical ionospheric prediction models. In such models the influence of the solar variability is the most important external factor.

- The trends in the E-region (lowering of $h^{\prime} \mathrm{E}$, increase of $f o \mathrm{E}$ ) are in qualitative agreement with an increasing greenhouse effect. However, the experimental trends are stronger than the model results. 


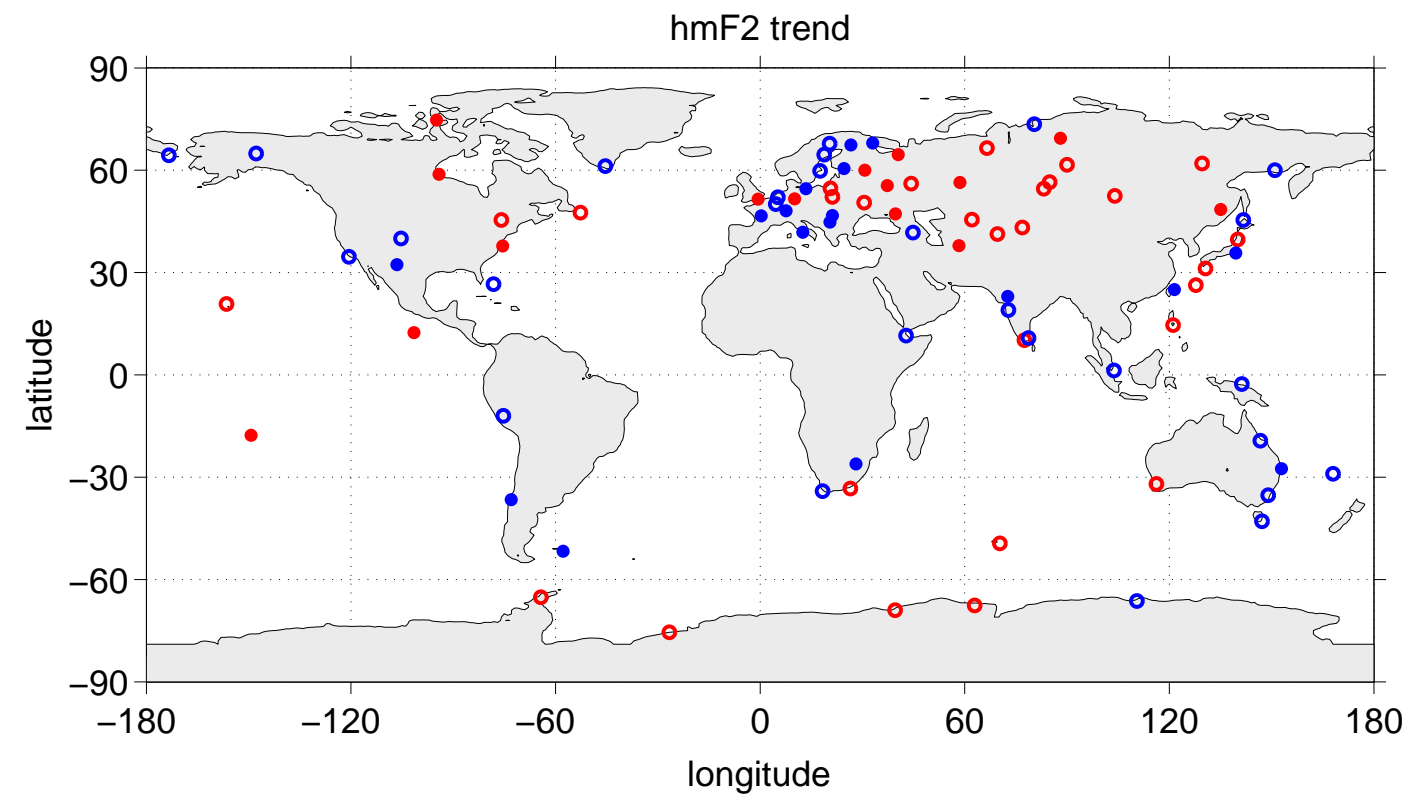

Fig. 5. Trends of $h m \mathrm{~F} 2$ observations at different ionosonde stations in dependence on latitude and longitude. Positive trends: red, negative trends: blue, significant trends: full dots, non significant trends: circles.

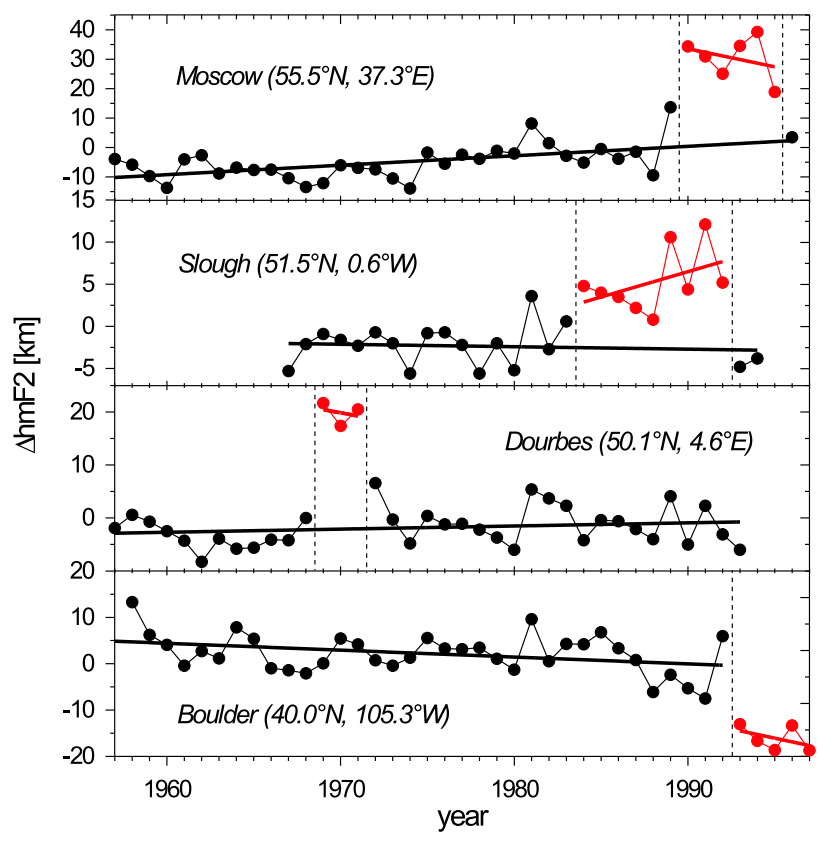

Fig. 6. Examples of individual $h m \mathrm{~F} 2$ trends after elimination of the solar and geomagnetic influences with discontinuities which could be caused by technical changes.

- The mean trend in the F1-region (increase of $f o \mathrm{~F} 1$ ) agrees quite well with model results of an increasing greenhouse effect.

- Due to a large variability of the individual trends in the F2-region no significant global trends could be derived for $f o \mathrm{~F} 2$ and $h m \mathrm{~F} 2$. Therefore, the relatively reasonable agreement between the mean global experimental and model results is accidental. The regional differences of the trends hint to an unknown dynamical process which superpose a possible greenhouse effect in the F2-region.

\section{References}

Akmaev, R. A.: Modeling of the cooling due to $\mathrm{CO}_{2}$ increases in the mesosphere and lower thermosphere, Phys. Chem. Earth, 27, 521-528, 2002.

Bencze, P., Sole, G., Alberca, L. F., and Poor, A.: Long-term changes of $h m \mathrm{~F} 2$ : possible latitudinal and regional variations, Proc. of the 2nd COST 251 Workshop, 30-31 March 1998, Side, Turkey, RAL UK, 107-113, 1998.

Brasseur, G. and de Rudder, A.: The potential impact on atmospheric ozone and temperature of increasing trace gas concentrations, J. Geophys. Res., 92, 10 903-10 920, 1987.

Bremer, J.: Trends in the ionospheric E- and F-regions over Europe, Ann. Geophys., 16, 986-996, 1998.

Bremer, J.: Trends in the thermosphere derived from global ionosonde observations, Adv. Space Res., 28, 7, 997-1006, 2001

Danilov, A. D. and Smirnova, N. V.: Long-term trends in the ion composition of the E-region (in Russian), Geomagn. Aeron., 37, 4, 35-40, 1997.

Hegerl, C. G., von Storch, H., Hasselmann, K., Sauter, B. D., Cubasch, U., and Jones, P. D.: Detecting greenhouse-gasinduced climate change with an optimal fingerprint method, J. Climate, 9, 2281-2306, 1996.

Houghton, J. T., Ding, Y., Groggs, D. J., Noguer, M., van der Linden, P. J., Dai, X., Maskell, K., and Johnson, C. A.: Climate Change: The Scientific Basis, Contribution of WG I to the 3rd Assessment Report of the IPCC, Cambridge, University Press, 2001.

Keating, G. M., Tolson, R. H., and Bradford, M. S.: Evidence of long term global decline in the Earth's thermospheric densities 
apparently related to anthropogenic effects, Geophys. Res. Lett., 27, 1523-1526, 2000.

Rishbeth, H.: A greenhouse effect in the ionosphere?, Planet. Space Sci., 38, 945-948, 1990.

Rishbeth, H. and Roble, R. G.: Cooling of the upper atmosphere by enhanced greenhouse gases - Modelling of the thermospheric and ionospheric effects, Planet. Space Sci., 40, 1011-1026, 1992.

Roble, R. G. and Dickinson, R. E.: How will changes of carbon dioxide and methane modify the mean structure of the mesosphere and thermosphere?, Geophys. Res. Lett., 16, 1441-1444, 1989.
Shimazaki, T.: World wide daily variations in the height of the maximum electron density in the ionospheric F2-layer, J. Radio Res. Labs., Japan, 2, 85-97, 1955.

Taubenheim, J.: Statistische Auswertung geophysikalischer und meteorologischer Daten, Akad. Verlagsgesellschaft Geest und Portig K.-G., Leipzig, 1969.

Ulich, Th. and Turunen, E.: Long-term behaviour of ionospheric F2-layer peak height on a global scale, Paper presented at Session 2.18 of the 8th Scientific Assembly of IAGA, Uppsala, 1997. 